Florida International University FIU Digital Commons

$2-17-1995$

\title{
International stock portfolio selection and performance measure recognizing higher moments of return distributions
}

Pornchai Chunhachinda

Florida International University

DOI: $10.25148 /$ etd.FI14060831

Follow this and additional works at: https://digitalcommons.fiu.edu/etd

Part of the Business Administration, Management, and Operations Commons

\section{Recommended Citation}

Chunhachinda, Pornchai, "International stock portfolio selection and performance measure recognizing higher moments of return distributions" (1995). FIU Electronic Theses and Dissertations. 2361.

https://digitalcommons.fiu.edu/etd/2361 


\section{FLORIDA INTERNATIONAL UNIVERSITY}

Miami, Florida

\section{INTERNATIONAL STOCK PORTFOLIO SELECTION}

\section{AND PERFORMANCE MEASURES RECOGNIZING HIGHER MOMENTS OF RETURN DISTRIBUTIONS}

A dissertation submitted in partial satisfaction of the requirements for the degree of

DOCTOR OF PHILOSOPHY

IN

BUSINESS ADMINISTRATION

by

Pornchai Chunhachinda

1995 


\section{To: Dean Harold Wyman. College of Business Administration}

This dissertation, written by Pornchai Chunhachinda, and entitled "International Stock Portfolio Selection and Performance Measure Recognizing Higher Moments of Return Distributions", having been approved in respect to style and intellectual content, is referred to you for judgement.

We have read this dissertation and recommend that it be approved.

$$
\text { Arun J. Prakash }
$$

Krishnan Dandapani

William W. Welch

Kenneth Bartunek

Shahid Hamid, Major Professor

Date of Defense: February 17, 1995

The dissertation of Pornchai Chunhachinda is approved.

Dean Harold Wyman

College of Business Administration

Dr. Richard L. Campbell

Dean of Graduate Studies

Florida International University, 1995 
I dedicate this dissertation to my parents. Without their encouragement, support, and most of all love, the completion of this work would not have been possible. 


\section{ACKNOWLEDGEMENTS}

I wish to thank the members of my dissertation committee, Dr. Hamid, Dr.

Prakash, Dr. Dandapani, Dr. Welch, and Dr. Bartunek, for their helpful comments, and especially for having the confidence in me to give me the chance to do this project.

Also special thanks must go to Dr. Parhizgari, Dr. Sullivan and Mr. Fang-Hui Shi, whose assistance and support were invaluable to the completion of this dissertation. 


\title{
ABSTRACT OF THE DISSERTATION \\ INTERNATIONAL STOCK PORTFOLIO SELECTION \\ AND PERFORMANCE MEASURES RECOGNIZING HIGHER MOMENTS \\ OF RETURN DISTRIBUTIONS
}

by

\author{
Pornchai Chunhachinda \\ Florida International University, 1995 \\ Professor Shahid Hamid, Major Professor
}

Since the seminal works of Markowitz (1952), Sharpe (1964), and Lintner (1965), numerous studies on portfolio selection and performance measure have been based upon the mean-variance framework. However, several researchers [ e.g., Arditti (1967, and 1971), Samuelson (1970), and Rubinstein (1973)] argue that the higher moments cannot be neglected unless there is reason to believe that: (i) the asset returns are normally distributed and the investor's utility function is quadratic, or (ii) the empirical evidence demonstrates that higher moments are irrelevant to the investor's decision. Based on the same argument, this dissertation investigates the impact of higher moments of return distributions on three issues concerning the 14 international stock markets.

First, the portfolio selection with skewness is determined using the Polynomial Goal Programming in which investor preferences for skewness can be incorporated. The empirical findings suggest that the return distributions of international stock markets are not normally distributed, and that the incorporation of skewness into an investor's portfolio decision causes a major change in the construction of his optimal portfolio. The evidence also indicates that an investor will trade expected return of the portfolio for skewness. Moreover, when short sales are allowed, investors are better off as they attain 
higher expected return and skewness simultaneously.

Second, the performance of international stock markets are evaluated using two types of performance measures: (i) the two-moment performance measures of Sharpe (1966), and Treynor (1965), and (ii) the higher-moment performance measures of Prakash and Bear (1986), and Stephens and Proffitt (1991). The empirical evidence indicates that higher moments of return distributions are significant and relevant to the investor's decision. Thus, the higher moment performance measures should be more appropriate to evaluate the performances of international stock markets. The evidence also indicates that various measures provide a vastly different performance ranking of the markets, albeit in the same direction.

Finally, the inter-temporal stability of the international stock markets is investigated using the Parhizgari and Prakash (1989) algorithm for the Sen and Puri (1968) test which accounts for non-normality of return distributions. The empirical finding indicates that there is strong evidence to support the stability in international stock market movements. However, when the Anderson test which assumes normality of return distributions is employed, the stability in the correlation structure is rejected. This suggests that the non-normality of the return distribution is an important factor that cannot be ignored in the investigation of inter-temporal stability of international stock markets. 


\section{TABLE OF CONTENTS}

CHAPTER

PAGE

I INTRODUCTION.

II INTERNATIONAL STOCK PORTFOLIO SELECTION WITH HIGHER MOMENTS.

2.1 Prior Contributions on Higher-Moment Portfolio Selection............ 4

2.2 The Empirical Applications of Multi-Objective Portfolio Selection.... 7

2.3 The Specification of Data...................................... 14

2.4 The Methodology

A. Testing for Normality of Return Distributions.................. 15

B. The Multi-Objective Portfolio Selection with Skewness........... 20

2.5 The Empirical Results...................................... 24

2.6 The Conclusions................................................. 31

III THE PERFORMANCE OF INTERNATIONAL STOCK PORTFOLIO ... 43

3.1 Prior Contributions on Higher-Moment Performance Measure......... 43

3.2 The Empirical Applications of Higher-Moment Performance Measure. 44

3.3 The Methodology ........................................ 50

3.4 The Specification of Data................................... 51

3.5 The Empirical Results...................................... 52

3.6 The Conclusions........................................... 58 
IV THE INTER-TEMPORAL STABILITY OF INTERNATIONAL STOCK MARKET RELATIONSHIPS ......................................... 66

4.1 The Potential Gains from International Diversification and the Controversy of Inter-Temporal Stability. 66

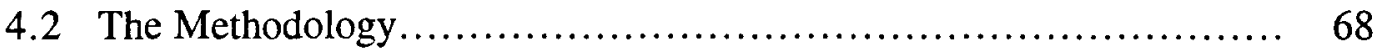

4.3 The Specification of Data......................................... 69

4.4 The Empirical Results........................................ 70

4.5 The Conclusions........................................ 75

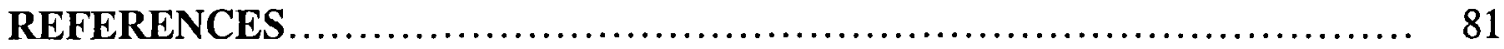

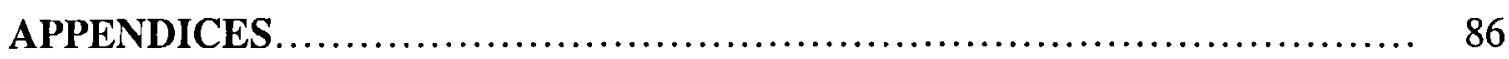

A. The Derivation of Three-Moment Portfolio Efficient Set............ 86

B. The Derivation of Higher-Moment Performance Measure............ 93

C. The Algorithm for the Sen and Puri Test......................... 98

VITA. 101 


\section{LIST OF TABLES}

TABLE

PAGE

2.1 Summary Statistics and Results for Normality Tests of International Stock Market Return Distributions.

2.2 Summary of Covariances for Weekly Returns of International Stock Markets.. 34

2.3 Summary of Covariances for Monthly Returns of International Stock Markets. 35

2.4 Summary of Coskewness (Curvilinear) for Weekly Returns of International Stock Markets

2.5 Summary of Coskewness (Curvilinear) for Monthly Returns of International Stock Markets.

2.6 Coefficient of Variation Rankings of International Stock Markets........... 38

2.7 The Polynomial Goal Programming of Weekly Optimal Portfolio Solution.... 39

2.8 The Polynomial Goal Programming of Monthly Optimal Portfolio Solution... 40

2.9 The Optimal Portfolio Selection Allowing No Short Sales.

2.10 The Optimal Portfolio Selection Allowing Short Sales

3.1 Summary Statistics and Coefficient of Variation Rankings of International Stock Markets. 59

3.2 Summary of Co-Moments Between International Stock Markets and World Equity Index 60

3.3 The Results of OLS Regression on Weekly Rates of Return................. 61

3.4 The Results of OLS Regression on Monthly Rates of Return................ 62

3.5 The Performance Rankings of International Stock Markets................. 63 
3.6 The Correlations of Stock Market Rankings Between Two Performance Measures.

3.7 The Correlations of Stock Market Rankings Between Weekly and Monthly Investment Horizons.

4.1 The Correlation Coefficients for Weekly Rates of Return of International Stock Markets.

4.2 The Correlation Coefficients for Monthly Rates of Return of International Stock Markets.

4.3 Dependency (Independency) Indexes of International Stock Markets (for Weekly Rates of Return)

4.4 Dependency (Independency) Indexes of International Stock Markets (for Monthly Rates of Return).... 79

4.5 The Testing Results of Equality of Correlation Matrices. 80 


\section{LIST OF FIGURES}

FIGURE

PAGE

A.1 The Three-Moment Portfolio Efficient Frontier............................ 90

A.2 The Efficient Frontier Projected on Mean-Standard Deviation Plane......... 91

A.3 The Three-Moment Portfolio Efficient Set............................. 92 


\section{INTERNATIONAL STOCK PORTFOLIO SELECTION}

\section{AND PERFORMANCE MEASURES RECOGNIZING HIGHER MOMENTS \\ OF RETURN DISTRIBUTIONS}

\section{CHAPTER I \\ INTRODUCTION}

Since the seminal works of Markowitz (1952), Sharpe (1964), and Lintner (1965), numerous studies on portfolio selection and performance measure have been based upon only the first two moments of return distributions. However, Arditti (1967, and 1971), Samuelson (1970) and Rubinstein (1973) argue that the higher moments cannot be neglected unless there is reason to believe that: 1) the asset returns are normally distributed and the investor's utility function is quadratic, or 2) the empirical evidence demonstrates that higher moments are irrelevant to the investor's decision.

In fact, there is ample empirical evidence [e.g. Fama (1965), Arditti (1971), and Simkowitz and Beedles (1978)] which indicates that individual security and portfolio returns are not normally distributed. Several studies including Arditti (1967, and 1971), Jean (1971, and 1973), and Levy and Sarnat (1972) also demonstrate that skewness is an important factor in explaining the security and portfolio returns. Samuelson (1970) shows that the higher moment is relevant to the investor's decision on portfolio selection. Moreover, Hanoch and Levy (1970), and Levy and Sarnat (1972) point out that the quadratic utility function is subject to some serious drawbacks. Other studies [e.g. 
Bierwag (1974), Borch (1974), and Levy (1974)] also question the adequacy of using a quadratic approximation for the utility function in practical applications.

Thus, this study is developed based on the earlier argument that the higher moments of return distributions are relevant to the investor's decision, and cannot be neglected. The objective of this study is threefold. First, the application of the portfolio selection with skewness is illustrated with the analysis of 14 selected international stock markets. However, in the presence of skewness, selecting a portfolio is a trade-off between competing and conflicting objectives, i.e., the investor tries to maximize the expected return and positive skewness, and minimize the variance simultaneously. To solve this multi-objective portfolio problem, this study extends the work of Lai (1991), and utilizes the Polynomial Goal Programming in which investor preferences for skewness can be incorporated. Then, the portfolio weights of the mean-variance-skewness efficient portfolio are obtained, and compared to those of the mean-variance efficient portfolio.

Second, this study evaluates the performance of the sample of 14 international stock markets using two types of performance measures:

1) The traditional two-moment performance measures of Sharpe (1966), and Treynor (1965), and

2) The more recently developed higher-moment performance measures of Prakash and Bear (1986), and Stephens and Proffitt (1991).

The two-moment performance measures, however, are subject to the same criticism as the mean-variance portfolio selection, especially when the return distributions 
of international portfolios are not symmetrical. Hence, the performance measures that incorporate higher moments seem to be more appropriate because they utilize a more complete description of the underlying return generating process.

Finally, this study investigates the inter-temporal stability of the international stock markets during the period from 1988 to 1993 . The inter-temporal relationships among international stock markets are important in helping the investors to realize the potential gains from international diversification. Under the stable correlation structure, investors can use the ex post patterns of co-movement of international stock markets as proxies for the ex ante co-movements, and select the optimal strategy from the ex post efficient frontier.

The remainder of this dissertation is organized in three chapters. Each chapters is self-contained, and serves each of the three objectives of this study. However, these three chapters are related by the central theme of the study, i.e., the higher moments of return distributions are relevant to the investor's decision, and cannot be neglected.

Thus, Chapter II discusses the empirical applications of Polynomial Goal Programming which is used to solve the multiple-objective portfolio selection. The methodology and the specification of data are also presented. Then, the mean-varianceskewness efficient portfolios are constructed. Chapter III discusses the empirical applications of higher-moment performance measures, followed by the presentation of the methodology employed. Then, the performance of the 14 international stock markets are evaluated. Chapter IV discusses the methodology for testing the inter-temporal stability of the correlation matrices. Then, the empirical findings are reported. 